\title{
Research on Style of Urban Rail Transit Vehicles from the Cultural Cognition
}

\author{
Xie Xuanhui \\ Southwest Jiaotong University \\ Chengdu 610031, China
}

\begin{abstract}
Under the background of cultural globalization, from the perspective of design cognition, it is studies the relationship between the cultural characteristics of the urban rail transit vehicle styling design. Based on the analysis of the engineering and aesthetic factors of the design of urban rail transit vehicles, the key areas of urban rail transit vehicle modeling design are summarized in combination with the cognitive characteristics of vehicle modeling. Based on the characteristics of The Times, cultural characteristics and aesthetic characteristics, the multi-dimensional matching model of urban rail transit vehicle modeling design and culture is established. It is provides theoretical support to enhance the cultural connotation of Chinese urban rail transit vehicle modeling design.
\end{abstract}

Keywords-Design cognition; Cultural characteristics; Urban rail transit vehicles; Form design

\section{INTRODUCTION}

Urban rail transit is an integral part of modern urban public facilities, urban rail transit is not only the needs of People's everyday travel, but also the important transportation [1]. As an important part of urban rail transit system, urban rail transit vehicles is one of the important means to disseminate urban cultural image. Urban rail vehicle form design involves mechanical manufacturing, engineering, social culture and the aesthetic characteristics of the times, it mainly includes the metro vehicle, the trams, inter-city railway and magnetic suspension new rail transit system [2]. With the development of the urban subway construction, Some scholars begin to pay close attention to urban rail vehicle design research, to the Xiangzerui research from the perspective of aesthetic principles of modern tram body overall modelling design [3]; Chenwei summarized the development trend of tram design at home and abroad [4]; Lijingjing and others have constructed the design method of streetcar modeling with regional characteristics [5]. Culture can be incorporated into the model of urban rail vehicle design has been gradually formed a trend, including how to deconstruct of cultural characteristics, with urban rail transit vehicles to the modern comprehensive mechanical equipment and the fusion matching each other is one of the problems to be solved. This article from the perspective of cultural cognition to the modelling of urban rail transit vehicle style as a research field, discusses the relationship between modern urban rail transit vehicle design style and culture development.

\section{CULTURAL COGNITION AND URBAN RAIL TRANSIT VEHICLES}

The urban rail transit vehicles is the products of modern industrial civilization, which have many advantages and features such as large passenger capacity, energy environment protection and running on time. With the accelerating process of urbanization in China, Urban rail transit industry is improve dramatically, by December 2016, more than 20 large and medium-sized cities in China established the urban rail transit construction project, it including about 100 subway lines with a total mileage of $3800 \mathrm{~km}$, Guangzhou, Tianjin, Qingdao, Dalian and so on more than 10 cities have built to city tram line the total distance of about $210 \mathrm{~km}$. Urban rail transit has gradually become an important part of the people life style in modern city, the form of Urban rail transit vehicles design is different from ordinary transport of the public services, It serves the general public, not personal consumer goods, the form design by engineering, aesthetic trend line positioning, aerodynamics, age comprehensive factors such as constraints, the form design of it is a concentrated reflection of various factors.

With the development of urban construction and social culture, urban rail transit vehicles is no longer just take a simple transportation function, as the material carrier of the city's image, one of its cars modelling design is the embodiment of the era aesthetic characteristics and the mental outlook. Culture is a multilevel, multi-faceted complex of material wealth and spiritual wealth created by mankind. Industrial design is the materialization of culture, and the design of the rail transportation tool for public service products is the epitome of social cultural change. Industrial product modeling design is the development and evolution of is closely connected with culture, cultural cognition is based on the cultural factors in the process of vehicle design of deconstruction, analysis its modelling design rule.

Project supported by the center for modern design and cultural studies,

E-mail:xiexuanhui@126.com. 


\section{THE EVOLUTION PROCESS OF URBAN RAIL TRANSIT VEHICLE MODELING STYLE}

Urban rail transit vehicles is accompanied by the development of urbanization, and the style design is influenced by engineering technology and social culture. The middle of the 18th century British industrial revolution opened the prelude of modernization, with the influx of large population, the British built the world's first subway lines in 1863, one of the earliest metro vehicle goes to produce [6]. German engineer Ernst Werner von Siemens has made the first electric streetcars in 1881, officially opened the prelude of tram development, technological advances will undoubtedly provides the driving force for urban rail transit vehicle, but early urban rail vehicle modelling is still mainly based on the modelling of the carriage vehicle, has strong classical color. With the continuous development of engineering and technology, especially the electrification technology matures, the world's large and medium-sized cities subway and light rail construction, industrial design gradually towards specialization, urban rail type gradually diversified development trend of urban rail vehicle style gradually formed their own characteristics, the diversified development trend, as shown in figure 1.
The development and maturity of culture are influenced by time and space, so the design culture has strong time characteristics and regional characteristics. As a typical representative of industrial products of urban rail transport, its modelling design is the materialized culture, because of the urban subway and tram both originated in Europe, in the early of the urban rail transit vehicle modelling is strongly influenced by European culture, the influence of culture embodied in the integral over the entire social structure, and will affect the aesthetic taste of The Times, from different periods of style characteristics of the urban rail transit vehicles can be seen that the early days of the urban rail transit vehicles, the influence of the traditional classical aesthetic, vehicle model has strong decorative means, after the development period, its modelling design adornment element further presents the trend of geometry, and post-industrial society, the further development of technology, the model of urban rail transit vehicles have the comprehensive innovation, the present law of synchronous change rule and the development of culture. In different periods of technological conditions, culture has created different aesthetic concepts, which are reflected in the design of industrial products. Due to the common characteristics of urban rail transit vehicles, the development of cultural concepts is behind its evolution.
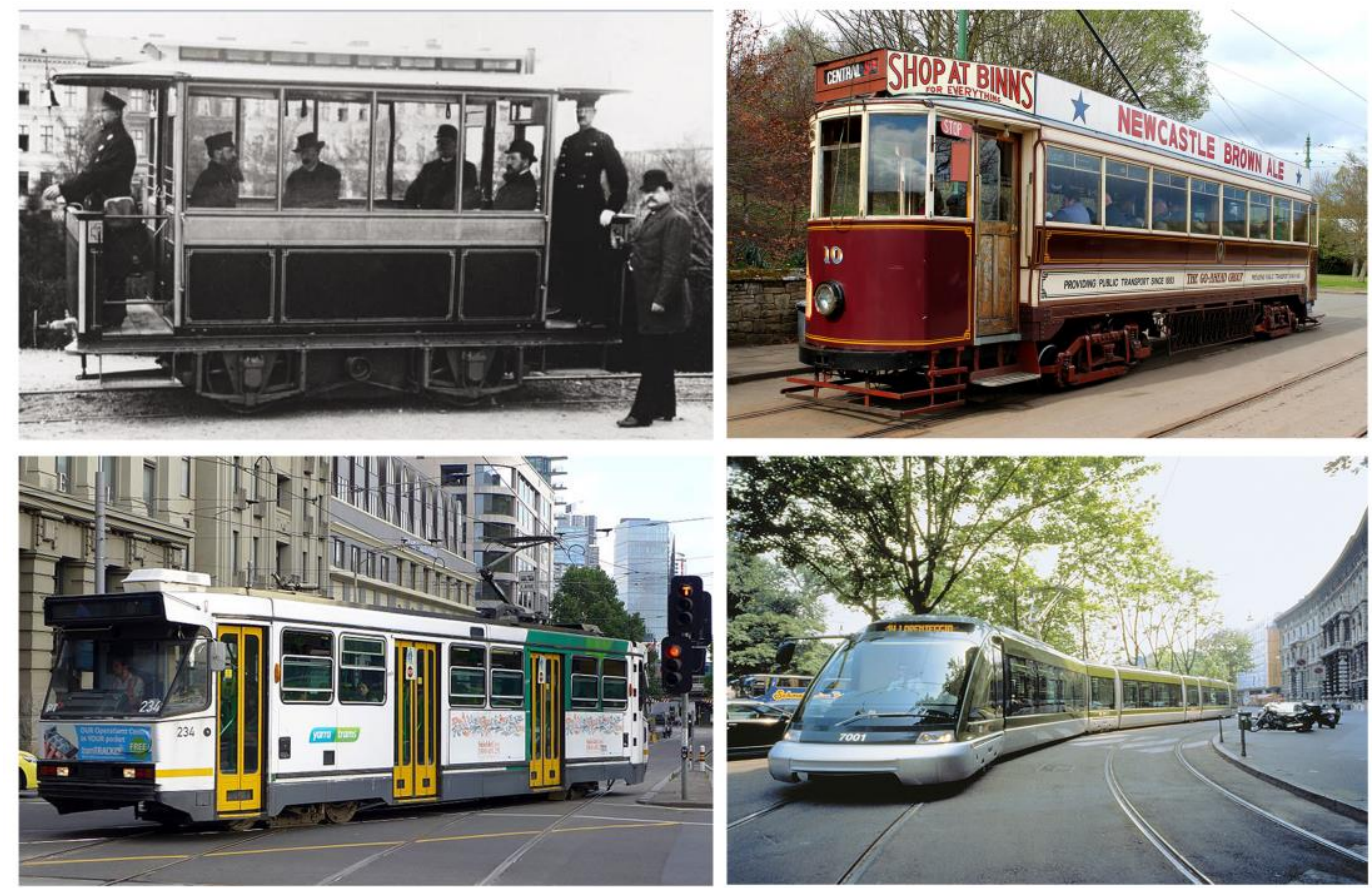

Fig. 1. Urban rail transit vehicle modeling style evolution

IV. THE RELATIONSHIP BETWEEN THE CHARACTERISTICS OF URBAN RAIL TRANSIT VEHICLES AND STYLE CHARACTERISTICS

The style is the most typical and unique language of the design case, which is embodied by geometric features of the physical shape of the vehicle. In the field of aesthetic research, style is mainly used to distinguish the aesthetic tendency of different periods and groups. In the field of art research, style describes the uniqueness of art content and techniques to describe different art schools and thoughts [7]. Whether it is the work of art or the study of literature, the most characteristic of style is its identification. The style of industrial product modeling design is modelling the geometrical characteristics of the entity, such as shape, size and proportion of the specific physical combination brings a person perception, can design style can be described as consisting of a series of products have a common characteristic of collection.

From a macro perspective, urban rail transit vehicle modeling includes: (1) front shape, (2) body shape, (3) vehicle 
decoration, (4) vehicle color painting. Above constitute each element model for urban rail vehicles, features, style characteristic comes from its all child elements, but also affected by vehicle integral form, relations of each feature and integral form are shown in table 1.

TABLE I. COMBINATION OF URBAN RAIL TRANSIT VehicLES Form DESIGN

\begin{tabular}{|l|l|l|}
\hline $\begin{array}{l}\text { The Whole of the } \\
\text { vehicle }\end{array}$ & Element composition & $\begin{array}{l}\text { Color painting of } \\
\text { vehicle }\end{array}$ \\
\hline Head of vehicle styling & $\begin{array}{l}\text { Roof cover, Display device, Front window, } \\
\text { Driver room side window and column, Lamp of } \\
\text { vehicle, Face mask, Coupler cover }\end{array}$ & $\begin{array}{l}\text { Color painting of } \\
\text { Vehicle head }\end{array}$ \\
\hline Body of vehicle styling & Side Windows, Door, Connection module & Decoration color \\
\hline Vehicle decoration & Detail decoration & $\begin{array}{l}\text { Decorative color, } \\
\text { Advertising painting }\end{array}$ \\
\hline
\end{tabular}

V. THE INFLUENCE OF CULTURAL CHARACTERISTICS ON THE MODELING STYLE OF URBAN RAIL TRANSIT VEHICLES

\section{A. Decoration and classical}

Mechanization of Britain's industrial revolution opened the prelude of modernization, the establishment of the factory made a large number of population into the city, urban area is expanding, the progress of engineering and technology brought traffic way of change, the emergence of the urban rail transit is the product of the industrial revolution and urbanization development. The evolution of modern urban planning, architectural style for urban rail vehicle's style has a direct impact, early modelling of urban rail transit vehicle on the one hand, the restriction of the technical conditions, on the other hand, influenced by classical decoration style, the vehicle overall modelling and the modern vehicle difference is bigger, the vehicle did not connect the overall structure, overall modelling style has strong classical color. Comes as classical decoration design of urban rail transit to the transition of modern design, its modelling design has strongly adornment colour, with the continuous development of urban construction, modern architectural style is gradually replace traditional decoration style, but still retained the history and context, urban development of rail transit vehicles is a microcosm of the history development. Many European cities still retained a classical style of urban rail transit vehicles, by its unique modelling deep historical context, convey the city urban rail transit has become a culture of beautiful landscape, as shown in figure 2 .
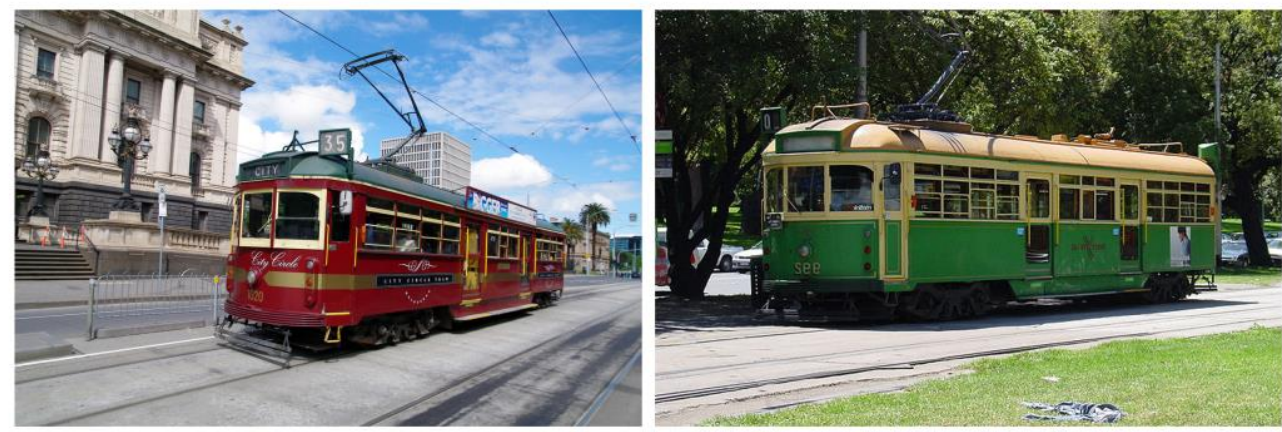

Melbourne tram
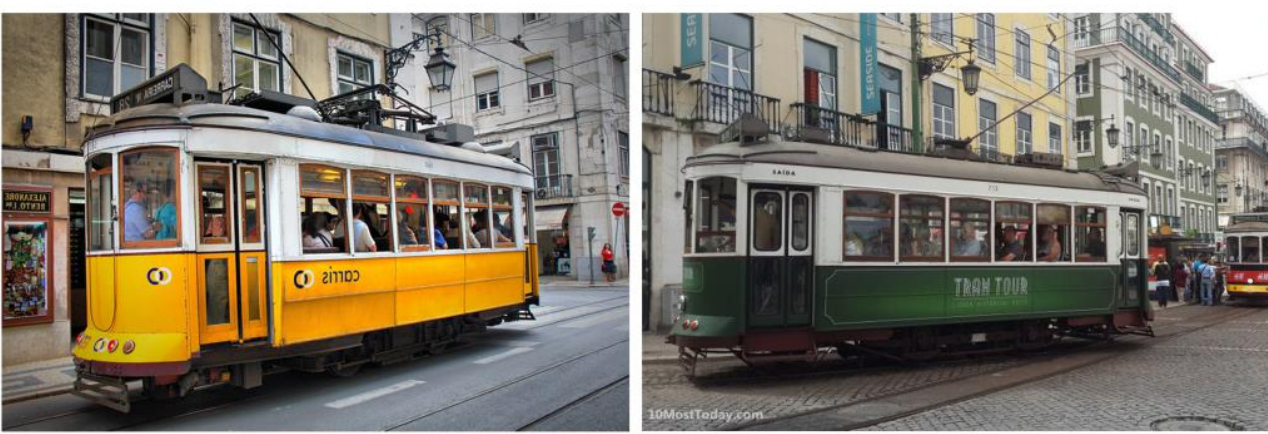

Lisbon tram

Fig. 2. Classic trams style 


\section{B. Modern technology aesthetics}

The continuous development of modern industrial technology for industrial product modeling design provides more possibilities, especially the aerodynamics, bionics and the intersection of design disciplines, modern product modeling provide a sense of science and technology step by step with The Times. Technology revolution is bound to bring the cultural revolution, industrial product design as one of the important carrier of human culture, the profound aesthetic style reflects the era, with the continuous development of rail transit vehicles equipped with processing and manufacturing technology, rail vehicle design gradually show more advanced aesthetic concept, the development of science and technology for rail transit vehicle design provides technical carrier of art, new art also make rail transit vehicles is a new aesthetic style, the development of city construction propelled the development of urban rail transit, and modern architectural style is no longer the decoration as the first elements of plastic arts, will bring the aesthetic cultural changes and evolution of transformation. At the same time, the design of urban rail transit vehicles is gradually shifting to a streamlined design with a sense of time and speed. Modern engineering and modeling aesthetics are integrated with each other, and the functional beauty of vehicle modeling, technical beauty and artistic beauty are mutually unified. Matures, along with the modern social structure of urban rail transit gradually to the comprehensive development trend of urban rail transit vehicle modelling design reflects the mechanization of modern society, technology, the digital aesthetic concepts. Modelling design directly affect the vehicle's overall visual effect, is the most direct expression of vehicle products, cultural regeneration brought the renewal of the city image, as an important part of the image of the city, urban rail transit vehicle model reflects the new idea of modern science and technology aesthetics, as shown in figure 3.
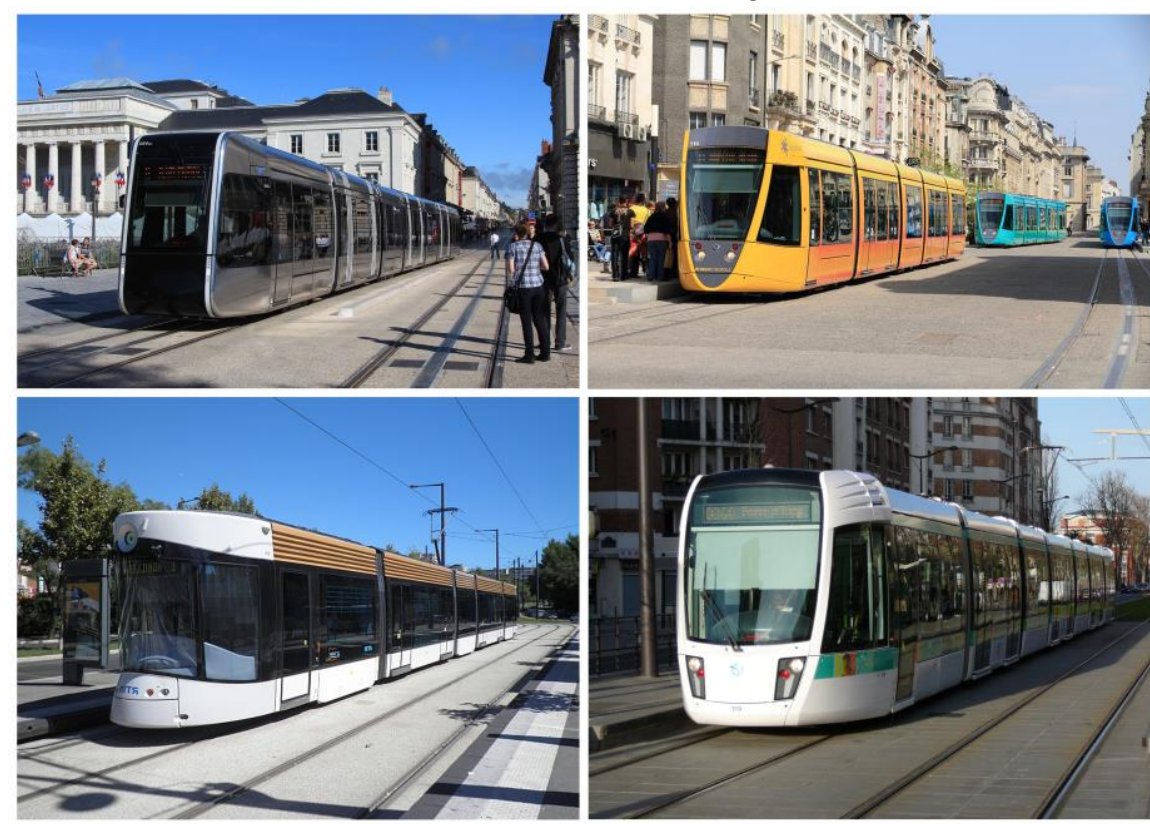

Fig. 3. Tram design with scientific and technological beauty

\section{Culture of commercial consumption}

Since the 1960s, the economic development of western developed countries has gradually entered the era of material abundance, and the social structure has been transformed from the production lead system to the consumption-led system. Consumption to guide the production, the function of industrial products demand is no longer the first, instead of product symbol function as its entering the market circulation, the first thing to do, urban rail transit vehicle does not belong to the individual consumer goods, it belongs to the public service facilities in the modern society, but in the transformation of culture, it will be affected by business consumption culture. As part of the modern urban landscape, urban rail transit vehicles is closely related to people's lives, with the advent of the consumption culture, the model of urban rail transit vehicle design is no longer merely cultural and aesthetic features. For example, the commonality of urban rail transit vehicles is the entry point of combining with commercial culture, and advertisement painting is widely used in modern urban rail vehicle modeling. The color of trams in European cities is painted, and the urban rail transit vehicles have gradually become mobile advertising vehicles, as shown in figure 4 . 

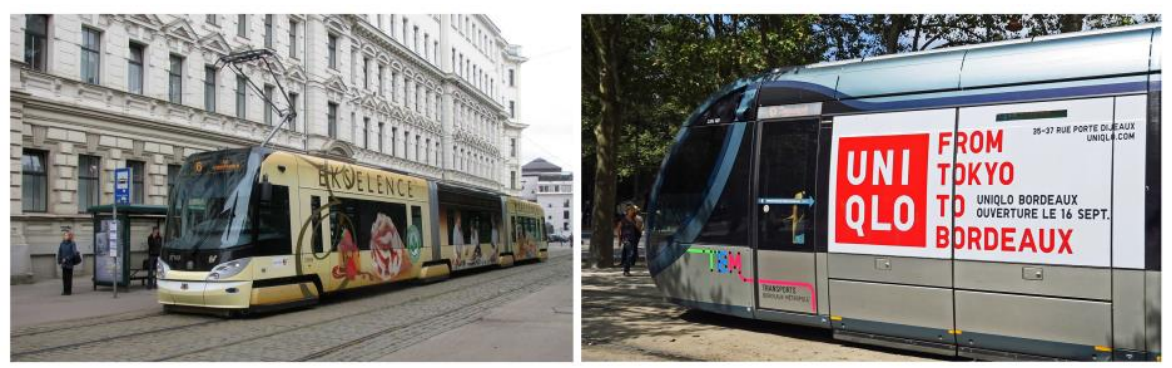

Fig. 4. Consumption culture and vehicle modeling design

\section{CONCLUSION}

Modern urban rail transit is the product of the development of human culture to a certain stage, it is both a sign of industrial technological progress, is also the embodiment of the culture and style as one of the most intuitive visual form of the rail transit vehicles, the design not only need to consider factors, at the same time also need to build the comprehensive cultural connotation. Urban rail transit vehicles as image is the important carrier of modern city image culture, from the Angle of cultural cognition, the study between culture and urban rail transit vehicle modelling design of the system, cultural characteristics and urban rail transit vehicle model to promote each other, each other is cause and effect of phased development course, research the evolution of the cultural characteristics and urban rail transit vehicle design, summarizes its characteristics, the regularity for the future of urban rail transit vehicle form design provides a new driving force.

\section{REFERENCES}

[1] WANG Chao. Research on Designs of Interior of Subway Vehicle [D].Chengdu: Southwest Jiaotong University, 2007.

[2] NIU Shao-fei, SHEN Zhon-gwei. Landscape Design of Urban Rail Transit Complex Based on the Concept of Sustainable Development [J]. Journal of Landscape Research, 2016 (08): 21-26.

[3] XIANG Zerui. Research on Styling Design of Modern Trams [D].Chengdu: Southwest Jiaotong University,2009.

[4] Chen Wei, DongShi-yu. Form Design of LRV Based on Culture of Three Kingdoms in Xiangyang $[\mathrm{J}]$. Packaging Engineering, 2017(06):145-149.

[5] LI Jing-jing, ZHI Jin-yi. Application of Regional Culture Symbol in Modern Tram's Design [J]. Packaging Engineering,2014(01):110-113.

[6] SHEN Yu-sheng. The subway culture and art [M]. Beijing: China railway Press, 2015.

[7] Chiu-Shui Chan. Can style be measured? [J]. Design Studies , 2000, 21: 277- 291. 